\title{
Systemic lupus erythematosus in the elderly: clinical and immunological characteristics
}

\author{
Josep Font, Lucio Pallarés, Ricard Cervera, Alfons López-Soto, Margarita Navarro, \\ Xavier Bosch, Miguel Ingelmo
}

\begin{abstract}
Systemic lupus erythematosus (SLE) predominantly affects young women in their $20 \mathrm{~s}$. In 40 out of $250(16 \%)$ patients with SLE seen in our hospital disease onset occurred after the age of 50 . The interval between the time of onset and diagnosis was five years in this older group compared with three years in the younger group. Arthritis, as a first symptom, was less common in the older onset group. During the follow up a lower incidence of arthritis, malar rash, photosensitivity, and nephropathy was found in the older onset group. In contrast, this group showed an increased incidence of myositis. High titres of anti-dsDNA tended to occur less often and the incidence of anti-Ro antibodies was lower in the older onset group. These features seem to distinguish patients with older onset SLE as a particular subset.
\end{abstract}

Systemic lupus erythematosus (SLE) predominantly affects young women in their 20 s. In $10-20 \%$ of patients, however, the diagnosis is made for the first time in the fifth decade of life or later. ${ }^{12}$

Several investigators have reported that age at onset has a modifying effect on disease expression. In comparison with younger patients, elderly patients with SLE are reported to have a more insidious onset of disease and less common occurrence of the classic manifestations of SLE. ${ }^{1-9}$ Thus the correct diagnosis is often not made for several years and is established only after extensive diagnostic evaluation. ${ }^{23}$ It has also been noted that certain features of SLE usually associated with severity, such as nephritis or central nervous system dysfunction, are less common in patients with older-onset SLE. ${ }^{12}$ In addition, serological abnormalities have also been reported to be different in elderly patients. $^{246-9}$ The disparity in selection criteria for patient inclusion, the age limits adopted, or the definition of age at onset make comparison of findings in previous reports very difficult.

In this study, to determine whether any relation exists between disease patterns and age at onset, we analysed prospectively the clinical course and immunological features in a series of 250 unselected patients with SLE.

Patients and methods

PATIENTS

Two hundred and fifty patients with SLE consecutively attending the Hospital Clínic of Barcelona as inpatients or outpatients between
1980 and 1988 were studied prospectively. All were white and met the American Rheumatism Association revised criteria for SLE. ${ }^{10}$ In 40 the onset of disease, defined as the initial manifestation clearly attributable to SLE, occurred after the age of 50, and they represent the older onset group described in this report. The remaining 210 patients were diagnosed before the age of 50, and they represent the younger onset group. The age limit was established arbitrarily according to previous reports. ${ }^{1-9}$ Follow up ranged between four months and seven years (mean 63 (SD 54) months) with no significant differences between groups.

A detailed clinical and laboratory assessment according to a pre-established protocol was made of each patient, including $(a)$ age at diagnosis; (b) evidence of clinical renal disease (abnormal urine sediment, proteinuria greater than $500 \mathrm{mg} /$ day, or otherwise unexplained increase of serum creatinine above $110 \mu \mathrm{mol} / \mathrm{l}$ ); (c) occurrence of chronic renal failure; (d) central nervous system disease; $(e)$ cutaneous involvement; $(f)$ serositis (including pleuritis, pericarditis, or both); and (g) Raynaud's phenomenon.

Disease was judged to be clinically active when the following signs or symptoms were present (a) typical dermatitis; (b) arthritis; $(c)$ serositis; (d) central nervous system abnormalities (recent onset of chorea, seizures, psychosis, organic brain syndrome in the absence of offending drugs or known metabolic derangements, embolic cerebral vascular accidents); (e) thrombocytopenia $\left(<100 \times 10^{9} / 1\right) ;(f)$ haemolytic anaemia; $(g)$ vasculitis (biopsy); or (h) nephritis: recent onset of haematuria $(>10$ red blood cells/high power field) or casts, or proteinuria $>500 \mathrm{mg} / 24 \mathrm{~h}$, or a $25 \%$ increase in serum creatinine. The histological appearance of renal biopsy specimens was considered to be active when fresh cellular crescents, diffuse or focal active proliferation of endocapillary cells, tuft necrosis, capillary thrombosis, or vasculitis was present.

\section{LABORATORY STUDIES}

Antinuclear antibodies were determined by indirect immunofluorescence using mouse liver as substrate. Antibodies to dsDNA were determined by Farr's ammonium sulphate precipitation technique. Complement components (C3 and $\mathrm{C4}$ ) were estimated by radial immunodiffusion and $\mathrm{CH} 50$ by Lachmann's haemolytic technique. Circulating immune complexes were detected by the microcomplement consumption test. 
In addition, 190 patients were tested for the presence of precipitating antibodies to soluble nuclear and cytoplasmic antigens, including Ro(SSA), La(SSB), nRNP, and Sm by double immunodiffusion (Ouchterlony).

These 190 patients were also tested for the presence of antiphospholipid antibodies, including anticardiolipin antibodies and the lupus anticoagulant activity. The anticardiolipin antibodies were measured by an enzyme linked immunosorbent assay (ELISA) as described by Loizou et $a l^{11}$ and Gharavi et al ${ }^{12}$ with the minor modifications of Cowchock et $a^{13}$ and our own. ${ }^{14}$ The flatbottomed wells of microtitre plates (Nunc, Denmark) were coated with 30 $\mu \mathrm{l} / \mathrm{well}$ of cardiolipin (Sigma) suspended in ethanol at a final concentration of $50 \mu \mathrm{g} / \mathrm{ml}$. The test was modified by inclusion of a measurement of binding to the microtitre plates after blocking (with $10 \%$ fetal calf serum in phosphate buffered saline for two hours) without added cardiolipin. Every individual serum sample was tested on the same plate for binding to wells both coated and uncoated with cardiolipin, Results were expressed as a binding index (BI). The average value for the samples from the wells without cardiolipin was the non-specific BI, and with cardiolipin was referred to as the total BI. Thus the final specific BI was obtained by subtraction of the non-specific BI from the total BI. A study of 50 normal control serum samples showed a log-normal distribution of both IgG and IgM anticardiolipin antibody titres. Normal values were considered when the logarithms of the specific BI were below the 98th centile of cumulative normal distribution. The IgG anticardiolipin antibody titre was regarded as positive if a specific BI greater than

Table 1 Clinical features at the onset of systemic lupus erythematosus in the elderly compared with younger patients. Results are given as number (percentage)

\begin{tabular}{llcl}
\hline Manifestations & $\begin{array}{l}\text { Older onset } \\
(n=40)\end{array}$ & $\begin{array}{l}\text { Younger onset } \\
(n=210)\end{array}$ & $p$ Value \\
\hline Arthritis & $16(40)$ & $137(65)$ & $<0 \cdot 005$ \\
Malar rash & $8(20)$ & $65(31)$ & NS \\
Photosensitivity & $6(15)$ & $38(18)$ & NS \\
Raynaud's phenomenon & $9(23)$ & $37(18)$ & NS \\
Vasculitis & $2(5)$ & $10(5)$ & NS \\
Serositis & $7(18)$ & $23(11)$ & NS \\
Nephritis & $1(3)$ & $15(7)$ & NS \\
Pneumopathy & $2(5)$ & $4(2)$ & NS \\
Neuropsychiatric & $2(5)$ & $16(8)$ & NS \\
Thrombocytopenia & $4(10)$ & $13(6)$ & NS \\
Haemolytic anaemia & $3(8)$ & $5(2)$ & \\
Fever & $5(13)$ & $42(20)$ & $7(3)$ \\
Myositis & $4(10)$ & & \\
\hline
\end{tabular}

Table 2 Incidence of major clinical features during follow up of elderly compared with younger patients. Results are given as number (percentage)

\begin{tabular}{|c|c|c|c|}
\hline Manifestations & $\begin{array}{l}\text { Older onset } \\
(n=40)\end{array}$ & $\begin{array}{l}\text { Younger onset } \\
(n=210)\end{array}$ & p Value \\
\hline $\begin{array}{l}\text { Arthritis } \\
\text { Malar rash } \\
\text { Photosensitivity } \\
\text { Raynaud's phenomenon } \\
\text { Vasculitis } \\
\text { Serositis } \\
\text { Nephritis } \\
\text { Pneumopathy } \\
\text { Neuropsychiatric } \\
\text { Thrombocytopenia } \\
\text { Haemolytic anaemia } \\
\text { Fever } \\
\text { Myositis } \\
\text { Cardiomyopathy } \\
\text { Thrombosis }\end{array}$ & $\begin{array}{l}26(65) \\
11(28) \\
6(15) \\
12(30) \\
5(13) \\
13(33) \\
8(20) \\
4(10) \\
5(13) \\
10(25) \\
5(13) \\
16(40) \\
8(20) \\
1(3) \\
6(15)\end{array}$ & $\begin{array}{l}172(82) \\
118(56) \\
71(34) \\
60(29) \\
28(13) \\
63(30) \\
83(40) \\
8(4) \\
44(21) \\
44(21) \\
14(7) \\
92(44) \\
15(7) \\
13(6) \\
31(15)\end{array}$ & $\begin{array}{l}<0.02 \\
<0.002 \\
<0 \cdot 002 \\
\text { NS } \\
\text { NS } \\
\text { NS } \\
<0 \cdot 03 \\
\text { NS } \\
\text { NS } \\
\text { NS } \\
\text { NS } \\
\text { NS } \\
<0.02 \\
\text { NS } \\
\text { NS }\end{array}$ \\
\hline
\end{tabular}

2.85 (SD 3.77) was detected. A specific BI greater than $4.07(3.90)$ was defined as positive for IgM anticardiolipin antibodies. The lupus anticoagulant activity was detected by the method of Exner. ${ }^{15}$

\section{STATISTICAL ANALYSIS}

Conventional $\chi^{2}$ and Fisher's exact tests were used for analysing qualitative differences, Student's $t$ test for comparison of means in large samples of similar variance, and the nonparametric Mann-Whitney $U$ test for small samples for age differences between groups.

\section{Results}

PATIENTS

In 40 patients ( $16 \%$ ) disease onset occurred after the age of 50 . The mean age of this group at disease onset was 58 years (range 50-78) compared with 32 years $(8-48)$ for the younger onset patients. The interval between the time of onset and diagnosis was five years in the older group compared with three years in the younger group $(p<0.05)$. The male/female ratio was $4 / 1$ in the older group in contrast with $9 / 1$ in the younger one. All women in the older group were in the menopause at disease onset.

\section{CLINICAL MANIFESTATIONS}

Table 1 shows the presenting clinical manifestations for patients with disease onset before or after age 50 . The older group less often showed arthritis as a first symptom $(p<0.005)$. During the follow up analysis of cumulative clinical symptoms showed that the most significant difference between these two groups was a decreased incidence of arthritis $(\mathrm{p}<0.02)$, malar rash $(p<0.002)$, photosensitivity $(p<0.002)$, and nephropathy $(p<0.03)$ in the older onset group. In contrast, this group had a significantly increased incidence of myositis $(p<0.02)$ (table 2).

The incidence of other clinical features, including serositis, pulmonary disease, and central nervous system manifestations, did not differ significantly between the groups.

\section{IMMUNOLOGICAL ABNORMALITIES}

Table 3 gives the serological findings in relation to age. High titres of anti-dsDNA tended to occur less frequently in the older onset group $(\mathrm{p}<0.05)$, with a similar proportion of clinically active patients in both groups, indicating that titres of anti-dsDNA decreased with aging. The

Table 3 Serological features at the onset of systemic lupus erythematosus in the elderly compared with younger patients. Results are given as mean $(S D)$

\begin{tabular}{llll}
\hline Variable & $\begin{array}{l}\text { Older onset } \\
(n=40)\end{array}$ & $\begin{array}{l}\text { Younger onset } \\
(n=210)\end{array}$ & $p$ Value \\
\hline dsDNA (U/ml) & $33 \cdot 9(31 \cdot 7)$ & $50 \cdot 4(39 \cdot 2)$ & $<0 \cdot 05$ \\
C3 (mg/l) & $728(216)$ & $678(259)$ & NS \\
C4 (mg/l) & $239(166)$ & $220(139)$ & NS \\
CH50 (units) & $411(234)$ & $391(202)$ & NS \\
CICs (\%) & $22 \cdot 8(20 \cdot 2)$ & $29 \cdot 0(21 \cdot 0)$ & NS
\end{tabular}

$\overline{\mathrm{CIC}}=$ circulating immune complexes. 
Table 4 Incidence of antiphospholipid antibodies and antibodies to extractable nuclear antigens at the onset of disease of elderly compared with younger patients. Results are given as number (percentage)

\begin{tabular}{lcll}
\hline Antibodies & $\begin{array}{l}\text { Older onset } \\
(n=40)\end{array}$ & $\begin{array}{l}\text { Younger onset } \\
(n=150)\end{array}$ & $p$ Value \\
\hline Antiphospholipid antibodies & $25(63)$ & $58(39)$ & $<0 \cdot 01$ \\
Ro(SSA) & $4(10)$ & $57(38)$ & $<0 \cdot 02$ \\
La(SSB) & $2(5)$ & $22(15)$ & NS \\
nRNP & $2(5)$ & $25(17)$ & NS \\
Sm & $5(13)$ & $27(18)$ & \\
\hline
\end{tabular}

incidence of detection of serum complement fractions $(\mathrm{C} 3, \mathrm{C4}, \mathrm{CH} 50)$ was similar in both groups.

The incidence of antiphospholipid antibodies (anticardiolipin antibodies or lupus anticoagulant, or both) was higher in elderly patients $(p<0.01)$. In contrast, the incidence of anti-Ro antibodies was lower in this group of patients $(\mathrm{p}<0.02)$. No significant differences were found in the incidence of the other antibodies to extractable nuclear antigens between the two groups (table 4).

\section{Discussion}

Systemic lupus erythematosus is a chronic inflammatory disorder of unknown cause with a wide spectrum of both clinical and immunological features. Although it has traditionally been considered a disease of young women, several reports have described SLE in the elderly. ${ }^{1-9}$ Nevertheless, overall experience with older-onset SLE is not extensive and the precise prevalence of clinical and serological findings differs from study to study. ${ }^{1} 246$ 16-19

In our series 40 out of 250 patients with SLE (16\%) developed the disease after the age of 50 - a prevalence similar to that noted by others $^{124}$ using similar criteria for selection of patients. In addition, although some authors ${ }^{2} 7$ found no difference in the female/ male ratio with aging, our observations suggest that female predominance is not so pronounced in the elderly onset group.

The clinical expression of SLE in elderly patients differs in several aspects from the disease in young adults. ${ }^{1-9}$ The presenting manifestations in the patients with older onset disease are interesting, and best resemble those in patients with drug induced SLE, primary Sjögren's syndrome, or polymyalgia rheumatica. ${ }^{1478}$ Thus in our series musculoskeletal manifestations, including myositis mimicking polymyalgia rheumatica, were common. Although some authors ${ }^{16716}$ have reported that serositis and pulmonary disease were the most common presenting features in their patients, we found a similar incidence of these manifestations in both groups. In addition, our patients share many similarities with other patients with older onset SLE previously reported, including a low incidence of lupus nephropathy and classical arthritis and cutaneous involvement. ${ }^{127}$

Age also influences the serological manifestations of SLE. Lower anti-dsDNA titres were found in our patients with older onset SLE. Similar results have been reported by Wilson et $a l .{ }^{4}$ It has been suggested that antibodies to Ro and $\mathrm{La}$ are more prevalent in elderly patients and might be a useful aid in establishing the diagnosis of SLE. ${ }^{267}$ In our study, however, the prevalence of these antibodies tended to decrease in the older onset group. Similar results have been found by others. ${ }^{20}$ Interestingly, we found a higher prevalence of anti-Sm antibodies, both in younger and elderly patients, than previously reported in other European studies. ${ }^{21} \mathrm{We}$ also detected a higher prevalence of antiphospholipid antibodies in the elderly group. This is in agreement with the findings of Manoussakis et $a l^{22}$ that anticardiolipin antibodies are commonly found in the elderly population.

Interestingly, the initial diagnosis in the older group was tardy, presumably because doctors are reluctant to diagnose SLE in elderly patients and because atypical signs and symptoms in this age group are common. This is reflected in our series in the mean five year delay in establishing the diagnosis of SLE in the older onset group. High clinical awareness is important as it is expected that increasing numbers of people will survive into the later years of life during the next decades. Thus it is reasonable to expect that more patients with older onset SLE will be diagnosed in the future. ${ }^{23}$

Although the explanation for this apparently age related variability in expression of the disease is still unclear, demographic factors and differences in genetic predisposition or responsiveness of an aging immune system may be implicated. ${ }^{38}$ It has been suggested that older and younger patients may have different genetic determinants of disease and respond to different triggering mechanisms. ${ }^{623}$ Alternatively, the less exuberant expression of SLE both clinically and immunologically in older patients may reflect senescence of the immune system. ${ }^{24}$

Our knowledge of the clinical and epidemiological aspects of SLE in the elderly has increased substantially in the last few years. Many questions await further analysis from a genetic and immunological perspective, however.

Supported in part by grants from the Hospital Clínic i Provincial of Barcelona to Dr Ricard Cervera and Dr Alfons López-Soto.

1 Baker S B, Rovira J R, Campion G V, Mills J A. Late onset systemic lupus erythematosus. Am $\mathcal{F}$ Med 1979; 66: 727-32. 2 Hochberg M C, Boyd R E, Ahearn J H. Systemic lupus erythematosus: a review of clinicolaboratory features and immunogenetic markers in 150 patients with emphasis on immunogenetic markers in 150 patients with emphasis on

3 Foad B S I, Sheon R P, Kirsner A B. Systemic lupus erythematosus in the elderly. Arch Intern Med 1972; 130: 743-6.

4 Wilson H A, Hamilton M E, Spyker D A, et al. Age influences the clinical and serological expression of systemic lupus erythematosus. Arthritis Rherem 1981; 24: 1230-5.

5 Ballou S P, Khan M A, Kushner I. Clinical features of systemic lupus erythematosus. Differences related to race and age of onset. Arthritis Rheum 1982; 25: 55-60.

6 Catoggio L J, Skinner R P, Smith G, Maddison P J. Systemic lupus erythematosus in the elderly: clinical and serological characteristics. I R heumatol 1984; 11: 175-81.

7 Maddison P J. Systemic lupus erythematosus in the elderly. f Rheumatol 1987; 14 (suppl 13): 182-7.

8 Hashimoto H, Tsuda H, Hirano T, Takasaki Y, Matsumoto $T$, Hirose $S$. Difference in clinical and immunological findings of systemic lupus erythematosus related to age. findings of systemic lupus erythen

9 Jonsson $\mathrm{H}$, Nived $\mathrm{O}$, Sturfelt $\mathrm{G}$. The effect of age on clinical and serological manifestations in unselected patients with systemic lupus erythematosus. $\mathcal{f}$ Rheumatol 1988; 15: 505-9. 
10 Tan E M, Cohen A S, Fries J F, et al. The 1982 revised criteria for the classification of systemic lupuserythematosus. Arthritis Rherum 1982; 25: 1271-7.

11 Loizou S, MicCrea J D, Rudge A C, Reynolds R, Boyle C C Harris E N. Measurement of anticardiolipin antibodies by an enzyme-linked immunosorbent assay (ELISA) an enzyme-linked immunosorbent assay (ELISA); Imomanol 1985; 62: 738-45.

12 Gharavi A E, Harris E N, Asherson R A, Hughes G R V. Anticardiolipin antibodies: isotype distribution and phospholipid specificity. Ann Rherum Dis 1987; 46: 1-6.

13 Cowchock S, Fort J, Muñoz S, Norberg R, Maddrey $W$. False positive ELISA tests for anticardiolipin antibodies in sera from patients with repeated abortion, rheumatologic disorders and primary biliary cirrhosis: correlation with elevated polyclonal IgM and implications for patients with repeated abortion. Clin Exp Immunol 1988; 73: 289-94.

14 Cervera R, Font J, Lopez-Soto A, et al. Isotype distribution of anticardiolipin antibodies in systemic lupus erythematosus: prospective analysis of a series of 100 patients. Ann Rheum Dis 1990; 49: 109-13.

15 Exner T, Rickard K A, Kronenberg H. Studies on phospholipids in the action of a lupus coagulation inhibitor lipids in the action of a

16 Dinant J, Ginzler E M, Schlesinger M, et al. Systemic lupus erythematosus in the older age group: computer analysis. f Am Geriatr Soc 1979; 27: 58-61.

17 Urowitz M B, Stevens M B, Shulman L E. The influence of age in the clinical pattern of systemic lupus erythematosus. Arthritis Rheum 1967; 10: 319-20.

18 Gossat D M, Walls B. Systemic lupus erythematosus in later life. Med Y Aust 1982; 1 : 297-9.

19 Baer A N, Pincus T. Occult systemic lupus erythematosus in elderly men. $f A M A$ 1983; 249: 3350-2.

20 Bell D A, Rigby R, Stiller C R, Clark W F, Harth M, Ebers G. HLA antigens in systemic lupus erythematosus: relationship to disease severity, age at onset, and sex. I Rheumatol 1984; 11 : 475-9.

21 Clotet B, Guardia J, Pigrau C, al Incidence and clinical significance of anti-ENA antibodies in systemic lupus erythematosus. Estimation by counterimmunoelectrophoresis. Scand f R heumatol 1984; 13: 15-20.

22 Manoussakis M N Tzioufas A G, Silis M P, Pange P J E Goudevenos J, Moutsopoulos H M. High prevalence of anti-cardiolipin and other autoantibodies in a healthy elderly population. Clin Exp Immumol 1987; 69: 557-65.

23 Bell D A. SLE in the elderly. Is it really SLE or systemic Siögren's syndrome? f R heumatol 1988; 15: 723-4.

24 Stevens M B. Connective tissue disease in the elderly. Clin Rhew Dis 1986; 12: 11-32. 